\title{
Machado-Joseph disease type 3
}

INSERM

\section{Source}

INSERM. (1999). Orphanet: an online rare disease and orphan drug data base. MachadoJoseph disease type 3. ORPHA:276244

Machado-Joseph disease type 3 is a subtype of Machado-Joseph disease (SCA3/MJD, see this term) of milder severity characterized by late onset, slower progression, and peripheral amyotrophy. 